“C 2011 IEEE. Personal use of this material is permitted. Permission from IEEE must be obtained for all other uses, in any current or future media, including reprinting/republishing this material for advertising or promotional purposes, creating new collective works, for resale or redistribution to servers or lists, or reuse of any copyrighted component of this work in other works." 


\title{
New Axial Laminated-Structure Flux Switching Permanent Magnet Machine with 6/7 Poles
}

\author{
Wei Xu, Member, IEEE, Jianguo Zhu, Senior Member, IEEE, Yongchang Zhang, Member, IEEE, Youguang Guo, \\ Senior Member, IEEE, Gang Lei
}

School of Electrical, Mechanical and Mechatronic Systems, University of Technology, Sydney, NSW 2007, Australia

In this paper, one new axially-laminated structure flux switching permanent magnet machine (ALSFSPMM) with 6/7 (stator/rotor) poles is proposed. Different from the conventional flux-switching permanent magnet machine (FSPMM), the stator and rotor of ALSFSPMM are laminated parallel to the axial direction, which can make full usage of PM flux linkage, decrease part magnetic saturation, and reduce the iron loss particularly in the range of high speed. By the $2 \mathrm{D}$ model prediction of finite element algorithm (FEA), ALSFSPMM has lower cogging torque, stronger flux weakening ability, greater torque density, higher efficiency, etc., and hence it is an ideal candidate for the drive system of plug-in hybrid electrical vehicle (PHEV).

Index Terms-Axial laminated-structure flux switching permanent magnet machine (ALSFSPMM), finite element algorithm (FEA), cogging torque, flux weakening ability, iron loss, plug-in hybrid electrical vehicle (PHEV).

\section{INTRODUCTION}

B Y many researchers' hard work during the past decades, the flux switching permanent magnet machine (FSPMM) as a doubly-salient PM brushless machine has come into notice of automobile companies. In this machine, both windings and magnets are located in the stator, while the rotor is passive with great mechanical robustness. For inheriting the merits of both switched reluctance machine and traditional rotor-PM machine, it has good attributes of high torque / power density, high efficiency, excellent flux-weakening capability, strong robustness, and convenience of cooling [1-4].

However, the FSPMM with radial lamination has serious partial magnetic saturation for its nonlinear magnetic path, which maximal flux density is usually more than 2.0 Tesla occurring at the edges/tips of stator teeth or rotor poles. Moreover, the pole pairs in FSPMM equals to the number of rotor poles, which is larger than those of traditional rotorinserted PM machines. Hence its rated frequency of stator current is higher at one given speed. For example, it could reach $175 \mathrm{~Hz} @ 1500$ rpm in the structure of 6/7 (stator / rotor) poles. In this case, the iron losses especially beyond the rated speed are very evident so to decrease the output power, the torque / power density, the efficiency, etc.

The axially-laminated reluctance machine is well-known for its low iron loss especially at high frequencies, which is promising for the high speed applications [4, 5]. This paper presents a novel axial laminated-structure flux switching permanent magnet machine (ALSFSPMM), and gives evaluation on its typical performance criteria based on finite element algorithm (FEA).

\section{STRUCTURE OF ALSFSPMM}

The structure of ALSFSPMM with 6/7 poles is illustrated in Fig.1. Different from the traditional FSPMM, it has 6 and 7 axially laminated modules (U shape) in stator and rotor respectively, which are made of $0.3 \mathrm{~mm}$ high grain oriented silicon steel sheet (HIB). The rotor and stator laminations could be made according to their moulds shown in Figs. 2 to 4 respectively. In order to save time and cost of fabrication, the rotor has been made firstly. Each piece of lamination is combined by glue of Loctite ${ }^{\circledR} 325^{\mathrm{TM}}$, which has great strength to bear the maximal temperature of $177^{\circ} \mathrm{C}$. Each rotor module could be combined closely with each other and then with the shaft by plastics keys or pins. The stator modules could be made in two steps: (1) U shape lamination should be acquired as in Fig. 3. (2) U shape lamination could be pressed from two lateral sides strictly according to the structure of stator slot as in Fig. 4. Then they would be combined by winding and plastics, finally fixed tightly by two plastics caps located in inner and outer stator radii. The asymmetry air gap could be achieved by cutting the laminations along the axis. There is spacing between the laminations to produce high $d$-axis reluctance. The flux loops along each laminated steel, which makes full usage of PM, and decreases hysteresis losses both in the stator and rotor.



Fig.1. Structure of ALSFSPMM.



Fig. 3. U shape lamination of stator module (the first step).



Fig. 2. Rotor mould in use.

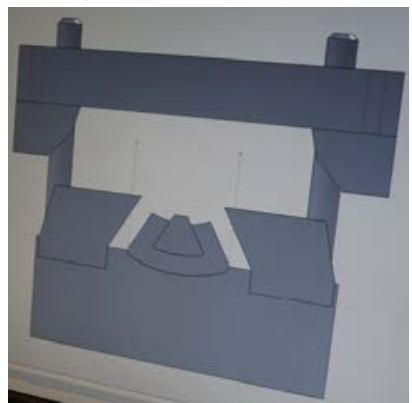

Fig. 4. Final lamination of stator module (the second step). 


\section{FinITE ELEMENT MODEL OF ALSFSPMM}

The effect of the stacking factor of ALSFSPMM is evaluated by FEA. It is modeled by specifying an anisotropic material in 2D model by modifying $\mathrm{BH}$ curves in the tangential and normal directions [2, 4-6]. The permeability in anisotropic material is described as

$$
\begin{aligned}
& \mu_{\text {norm }}=\frac{\mu_{\text {steel }} \mu_{\text {air }}}{v \mu_{\text {air }}+(1-v) \mu_{\text {steel }}} \\
& \mu_{\text {tang }}=v \mu_{\text {steel }}+\mu_{\text {air }}(1-v)
\end{aligned}
$$

where $\mu_{\text {steel }}, \mu_{\text {norm }}, \mu_{\text {tang }}, \mu_{\text {air }}$ are permeability of steel, normal direction of steel, tangential direction of steel and air gap respectively, and $v$ is the stacking factor.

However, the value of $\mu_{\text {steel }}$ is non-linear, hence it is not accurate to calculate the new BH curve just based on (1) and (2). One simple and method for getting the new anisotropic BH curve can be given by $[2,6]$ :

(i) In the normal direction, the flux density between the lamination and air gap is constant, so for a given flux density in the original BH curve, the value of the field strength in the normal direction can be expressed as:

$$
\begin{aligned}
& H_{\text {norm }}^{k}=v H_{\text {steel }}^{k}+(1-v) \frac{B_{\text {steel }}^{k}}{\mu_{0}} \\
& B_{\text {norm }}^{k}=B_{\text {steel }}^{k}
\end{aligned}
$$

where $H_{n o r m}^{k}$ is the $k^{\text {th }}$ value of the field strength of normal direction in the BH curve, $H_{\text {steel }}^{k}$ the $k^{\text {th }}$ value of the field strength of laminated steel in the BH curve.

(ii) In the tangential direction, the field strength is constant for both materials, hence for a given field strength, the flux density is calculated by

$$
\begin{aligned}
& B_{\text {tang }}^{k}=v B_{\text {steel }}^{k}+(1-v) \mu_{0} H_{\text {steel }}^{k} \\
& H_{\text {tang }}^{k}=H_{\text {steel }}^{k}
\end{aligned}
$$

This method is firstly used to analyze the 2D model of brushless doubly-fed reluctance machine in Ansoft Maxwell 12 by the help of the Global and Local (Fixed) coordinate systems in the Maxwell, and gets the similar results as [5]. Then it is adopted in 2D model of ALSFSPMM. By varying the $v$ from 0.4 to 1.0 , it is found that the optimal stacking factor is 0.5 for the maximal average torque.

\section{PERFORMANCE ANALYSIS AND COMPARISON}

In order to save time consumption, the only difference between the FEA model and real prototype being built up is that the number of axial rotor laminations is halved, i.e. the lamination and insulation layer thickness doubled, while the number of stator lamination are unchanged for some flux could run across different laminations. In this work, the machine is investigated by a series of static and transient solutions. It is decided to a current-feed machine, and the simulation is controlled by the external circuit. Simulation on the traditional FSPMM and ALSFSPMM has been done on the platform of Ansoft Maxwell 12. These two machines have the same physical dimensions as given in Table I. Based on the static and dynamic FEA models, comparison are made on the typical performance criteria, including flux density contour, PM flux linkage, cogging torque, rated torque, and torque/efficiency in the whole operation range.

TABLE I

MAIN Dimensions of TwO MACHINES (length unit: mm)

\begin{tabular}{ccc}
\hline \hline & Items & Value \\
\hline & Outer radius & 54.6 \\
& Yoke height & 8.8 \\
Stator & Number of poles & 6 \\
& Pole width & 23.6 \\
& Pole height & 13.8 \\
& Number of turns per pole winding & 78 \\
PM & Width & 6 \\
& Height & 22 \\
& Relative permeability & 1.03 \\
& Magnetic remanence [Tesla] & 1.19 \\
& Air gap length & 0.6 \\
Rotor & Pole width & 12.2 \\
& Pole height & 14.6 \\
& Yoke height & 6.1 \\
& Number of poles & 7 \\
& Radius of shaft & 10.6 \\
& Effective axial length & 49 \\
\hline \hline
\end{tabular}

\section{A. Contour of Flux Density}

There is serious partial magnetic saturation in the FSPMM with radial lamination for its nonlinear magnetic circuit inherited from the double salient structure in stator and rotor.

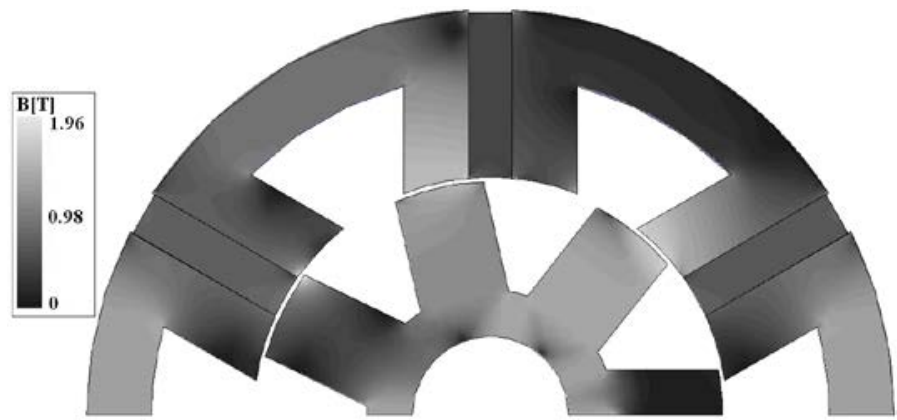

(a)

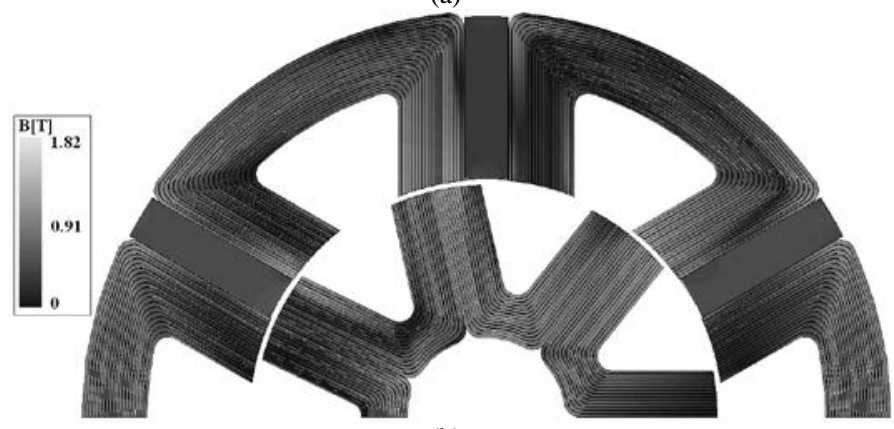

(b)

Fig.5. Flux density contour. (a) FSPMM. (b) ALSFSPMM.

By employing the axial lamination, ALSFSPMM could make full usage of the PM. Their flux density distributions are illustrated in Fig.5 (For the odd number of rotor pole, the flux density distributions in both machines are a little asymmetry. Here just half contours are given out to indicate different magnetic saturation levels briefly for the space limitation.). Under the excitation of the same size PM, the maximal flux density, 1.96 Tesla, occurs in edge of stator tooth or rotor pole in the FSPMM, greater than that of ALSFSPMM with 1.82 
Tesla. It can be seen that the ALSFSPMM could reduce the partial magnetic saturation in edges/tips of stator teeth and rotor poles.

\section{B. Flux Linkage and Cogging Torque}

The flux linkage is shown in Fig.6. By the electromagnetic optimal design, it seems sinusoidal, and hence could operate in the state of blushless AC (BLAC). For some flux linkages could go across different stator laminations, the average equivalent length of air gap along the flux path in ALSFSPMM is larger. Hence the flux is $1.7 \%$ smaller than that of FSPMM.

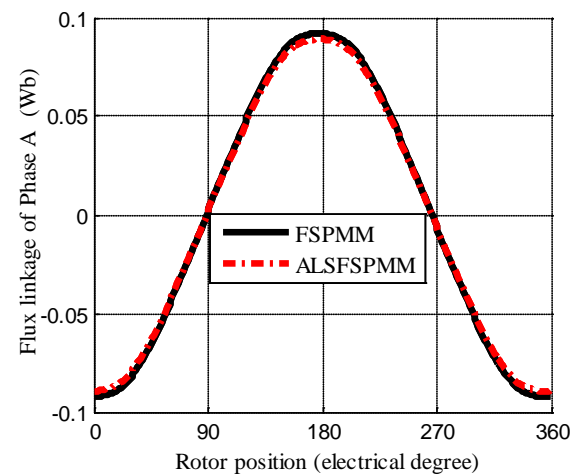

Fig.6. Flux linkage of phase-A.

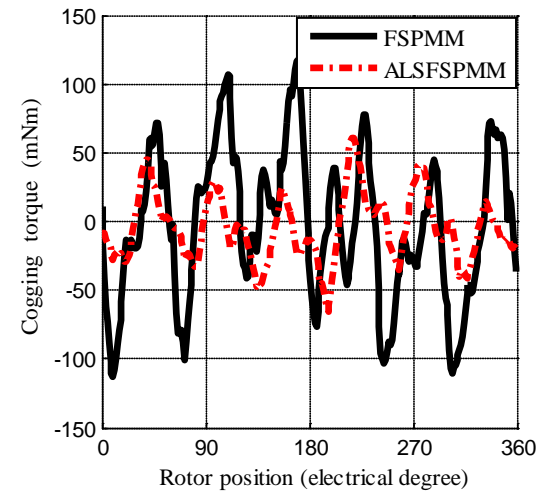

Fig.7. Cogging torque.

The cogging torque could bring some bad influence for the drive machine stable operation, which should be carefully considered in the process of optimal design. In general, it is closely relative with magnetic reluctance affected by the structure size, especially the widths of stator tooth and rotor pole, the depth of stator slot, the thickness of PM, etc. By the energy method and the Fourier series analysis, the cogging torque, $T_{\mathrm{c}}$, can be calculated by [3]

$T_{c}(\theta)=-\frac{\partial W(\theta)}{\partial \theta}=-\frac{\partial}{\partial \theta}\left\{\frac{1}{4 \mu_{0}}\left(R_{s p}^{2}-R_{r p}^{2}\right) \int_{0}^{L_{c f}} \int_{0}^{2 \pi} G^{2}(\alpha, z) B^{2}(\alpha, \theta) \mathrm{d} \alpha \mathrm{d} z\right\}$ (7)

where $\mu_{0}$ is the permeability of air, $\alpha$ the angle along the airgap circumference, $L_{\mathrm{ef}}$ the effective axial length of the machine, $z$ axial position along the machine axis, $G(\alpha, z)$ air-gap relative permeance, $B(\alpha, \theta)$ the air-gap flux density in an equivalent slotless machine, and $R_{\mathrm{sp}}$ and $R_{\mathrm{rp}}$ the inner radius of stator and outer radius of rotor respectively. The cogging torque is illustrated in Fig.7. For smaller $G(\alpha, z)$ in ALSFSPMM, its cogging torque is about $58 \%$ of that of FSPMM.

\section{Rated Torque}

In this prototype, the rated (base) speed is $1500 \mathrm{rpm}$, the input DC voltage of 3-phase inverter is $450 \mathrm{~V}$, and the stator current density is $6.5 \mathrm{~A} / \mathrm{mm}^{2}$. By the BLAC excitation, the rated torque is shown in Fig.8. For less partial electromagnetic saturation and less iron loss especially in rotor, the rated torque of ALSFSPMM is near $4.8 \%$ higher than that of FSPMM. It is obvious that the ALSFSPMM has smaller torque ripple (ratio of torque difference to average torque), $3.3 \%$, than that of FSPMM with $8.7 \%$.

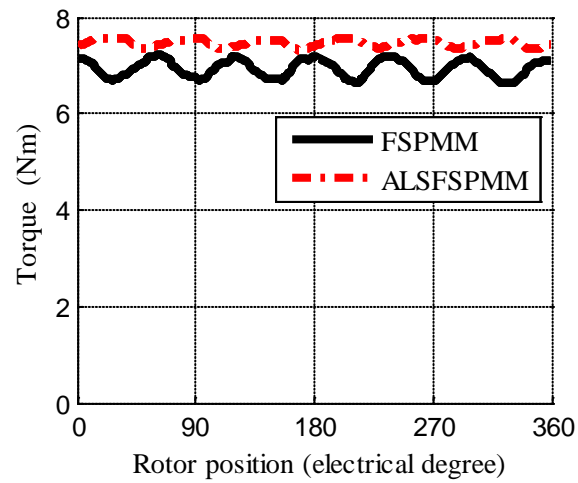

Fig.8. Rated torque @ 1500rpm.

\section{Flux Weakening Ability}

The FSPMM as a good candidate could be applied in the plug-in hybrid electrical vehicle (PHEV) [1, 3-5], whose typical torque/speed and power/speed curves are shown in Fig. 9. There are three regions: the constant torque region I (below

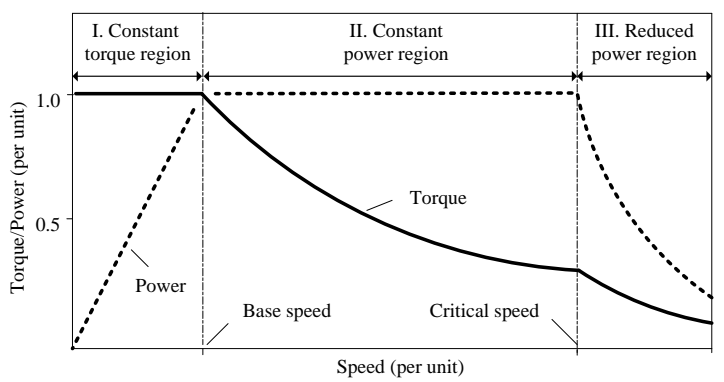

Fig.9. Torque and power versus speed curves.

the base speed), constant power region II (between the base speed and critical speed) and reduced power region III (above the critical speed). In Region I, the maximum torque capability is limited by the thermal or current rating of the electrical drive system while the machine terminal voltage increases linearly with the speed. At the base speed, both the voltage and current reach the limits (the rated values). In Region II, a flux weakening scheme is employed to further extend the operating speed range for the maximal voltage limitation where the torque decreases with the increasing speed for gradually attenuating current. In Region III, the torque and power collapse for ineffective field weakening - there is insufficient supply voltage to drive the system and this region should be avoided.

The flux weakening ability $\beta$ equal to the ratio of critical speed to the base one can be calculated by 


$$
\beta=\frac{\psi_{m}}{\psi_{m}-\psi_{d}}=\frac{\psi_{m}}{\psi_{m}-i_{d} L_{d}}
$$

where $\psi_{m}$ is flux linkage of PM, $i_{d}$ the $d$-axis current, and $L_{d}$ the $d$-axis inductance. By the evaluation of FEA, $\beta$ of ALSFSPMM is 4.45, while FSPMM 4.07. In relation to the road speed limits in Australia, the base speed would typically be $50 \mathrm{~km} / \mathrm{h}$, and the critical speed could be more than 200 $\mathrm{km} / \mathrm{h}$. Hence, the ALSFSPMM is an ideal candidate for the PHEV.

\section{E. Torque and Efficiency versus Different Speeds}

As stated in Section D, two machines are controlled to be operated in two areas, constant torque (below $1500 \mathrm{rpm}$ ) and constant power (above $1500 \mathrm{rpm}$ ). For the space constraint, just torque and efficiency are stated below.

Fig. 10 is the curve of torque versus speed. The machines are accelerated by the excitation of constant phase current, $5 \mathrm{~A}$, from 0 to $1500 \mathrm{rpm}$, where the phase voltage reaches the rated value, $220 \mathrm{~V}$, and then they enter the area of flux weakening for the voltage limitation. The torque gradually falls down for the decreasing air gap flux linkage by the modification of minus $d$-axis current. For greater magnetic saturation in FSPMM, its torque is about $5.1 \%$ smaller than that of ALSFSPMM in average. Moreover, the ALSFSPMM has greater $d$-axis inductance than that of FSPMM, hence its maximal operation range could reach almost $6700 \mathrm{rpm}$, a little wider than 6100 rpm in FSPMM.



Fig.10. Torque in versus speed.

Coarse evaluation on the efficiency of both machines has been done based on the personal experience and empirical equations. From the machine's view, the power loss mainly includes winding (copper) loss $P_{\mathrm{cu}}$, iron loss $P_{\text {iron}}$, friction loss $P_{\mathrm{f}}$, and stray loss $P_{\mathrm{s}}$. Generally speaking, $P_{\text {cu }}$ can be calculated by the Ohm's Law, while $P_{\mathrm{f}}$ and $P_{\mathrm{s}}$ could be estimated about $2 \%$ of the output active power, $P_{\text {out }}$. The iron loss $P_{\text {iron }}$ including hysteresis loss $P_{\mathrm{h}}$ and eddy current loss $P_{\mathrm{e}}$, could be estimated by [4-6],

$$
P_{\text {iron }}=P_{h}+P_{e}=k_{h} f B_{m}^{\alpha}+k_{e} f^{2} B_{m}^{2}
$$

where $f$ and $B_{\mathrm{m}}$ are the frequency and the peak value of the magnetic flux density, respectively; $k_{h}, k_{e}$ and $\alpha$ are the loss coefficients of HIB steel sheet provided by the supplier. Hence, the efficiency could be finally evaluated by

$$
\eta=P_{\text {out }} /\left(P_{\text {out }}+P_{c u}+P_{\text {iron }}+P_{f}+P_{s}\right)
$$

Fig.11 is the curve of efficiency versus speed. Below the base speed, the FSPMM and ALSFSPMM have similar efficiency, and 85.6\% and 86.9\% @1500 rpm. They get the maximal efficiency almost at $2000 \mathrm{rpm}$. As speed goes up further, the efficiency of FSPMM decreases more quickly than that of ALSFSPMM for the influence of greater iron loss.

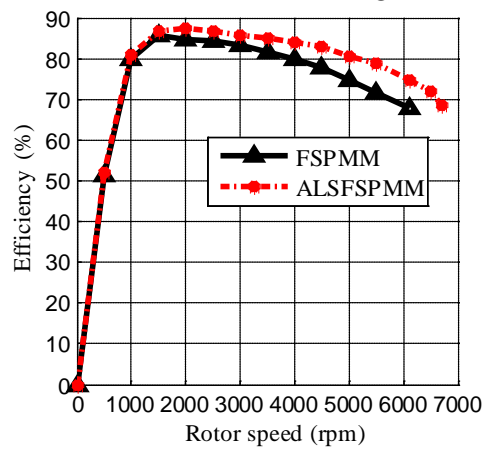

Fig.11. Efficiency versus speed.

\section{CONCLUSION}

By the help of FEA 2D model executed in Ansoft Maxwell 12, the paper illustrates that the ALSFSPMM is an ideal candidate for the PHEV for its higher flux weakening aiblity, torque density, efficiency etc. than those of the traditioanl FSPMM. For the axial laminations consisting of HIB in stator and rotor, the ALSFSPMM has smaller magnetic saturation and hence reduces iron loss especially in high speed (excition frequency). For the complexity of fabrication, further works include the completion of the whole prototype (rotor is completed currently) so to verify the practicality (or find another better solution to reduce the manufacture cost), further development of control system to investage the performance, evaluation of unbalanced magnet pull (UMP) from odd number of rotor poles (7 rotor modules could be enclosed as a whole, then some plastics would be inserted into 7 rotor slots to reduce UMP's influence), etc.

\section{ACKNOWLEDGEMENT}

Many thanks go to A/Prof. David G. Dorrell in the University of Technology Sydney, Australia for his kind help to our analysis of ALSFSPMM.

\section{REFERENCES}

[1] Z. Q. Zhu and J.T. Chen, “Advanced flux-switching permanent magnet brushless machines,” IEEE Trans. Magn., vol. 46, no.6, pp. 1447-1453, Jun. 2010.

[2] Vector Fields Limited, England, OPERA-2D Reference Manual, Version 10. 0, Feb. 2004.

[3] L. Zhu, S.Z. Jiang, Z.Q. Zhu, and C.C. Chan, “Analytical methods for minimizing cogging torque in permanent-magnet machines, " IEEE Trans. Magn., vol. 45, no.4, Apr. 2009, pp. 2023-2031.

[4] E. M. Shulz, "Optimal torque per amp for brushless doublyfed reluctance machines," in Proc. IEEE IAS Conf., 0ct. 2005, pp. 1749-1753.

[5] I.Scian, D.G. Dorrell, and P.J. Holik, “Assessment of losses in a brushless doubly-fed reluctance machine,” IEEE Trans. Magn., vol. 45, no.10, pp. 3425 - 3427, Oct. 2006.

[6] J.G. Zhu and V.S. Ramsden, "Improved formulations for rotational core 
losses in rotating electrical machines," IEEE Trans. Magn., vol. 34, no. 4, Jul. 1998, pp.2234-2242. 